\title{
Intracellular Calcium Concentrations during "Chemical Hypoxia” and Excitotoxic Neuronal Injury
}

\author{
Janet M. Dubinsky ${ }^{\mathrm{a}}$ and Steven M. Rothman \\ Departments of Anatomy and Neurobiology, and Pediatrics, Washington University School of Medicine, St. Louis, \\ Missouri 63110
}

\begin{abstract}
Because hypoxic/ischemic neurodegeneration appears to be in part linked to glutamate neurotoxicity, we measured intracellular calcium $\left(\mathrm{Ca}^{2+}\right)$ levels in cultured hippocampal neurons during exposure to toxic doses of glutamate (GLU) and to an anoxic environment simulated by sodium cyanide ( $\mathrm{NaCN}$ ). Changes in $\mathrm{Ca}^{2+}$, produced by cyanide greatly exceeded those induced by GLU. The NaCN response was mimicked when oxidative metabolism was also disrupted by sodium azide, oligomycin, or dinitrophenol. Noncompetitive NMDA receptor antagonists and enzymatic GLU degradation abolished the GLU-induced $\mathrm{Ca}^{2+}$, increases and attenuated those produced by $\mathrm{NaCN}$. Only $\mathrm{NaCN}$-induced increases were blocked when dantrolene and ruthenium red were applied to prevent release from intracellular pools. All responses were reduced proportionally in the absence of added external calcium. These results suggest that extracellular GLU accumulation and subsequent activation of GLU receptors were involved in the $\mathrm{NaCN}$ response. During such metabolic compromise, however, GLU-induced elevations of $\mathrm{Ca}^{2+}{ }_{i}$ were enormously amplified. In parallel toxicity studies, $\mathrm{NaCN}$ was not neurotoxic despite the large elevations in $\mathrm{Ca}^{2+}{ }_{i}$ indicating that a general elevation in cytoplasmic calcium does not necessarily predict neurodegeneration.
\end{abstract}

Van Harreveld (1959) first suggested a link between glutamate (GLU) and hypoxic neuronal damage because both produced spreading depression in rabbit cortex. Since then, the role of GLU as a neurotransmitter (Mayer and Westbrook, 1987) and a neurotoxin has been well established (Choi, 1990; Choi and Rothman, 1990). Excessive GLU, acting primarily through the NMDA class of excitatory amino acid receptors, has proved lethal to retinal, cortical, cerebellar, and hippocampal neurons in both in vivo and in vitro models (Rothman, 1984; Olney et al., 1986; Rothman et al., 1987; Choi et al., 1988; Manev et al., 1989).

During experimental ischemia, elevated GLU concentrations can be detected in brain by microdialysis (Benveniste et al.,

\footnotetext{
Received Oct. 1, 1990; revised Mar. 14, 1991; accepted Mar. 20, 1991.

We would like to thank Nancy Lancaster for preparation of the cultures, Eric Redleaf for software development, Dr. Tom Lanthorn for suggesting some of the experiments, and Roseann Hays for secretarial assistance. This work was supported by NIH Grant NS19988 and by the Monsanto Corporation.

Correspondence should be addressed to Dr. Steven M. Rothman, Department of Anatomy and Neurobiology, Box 8108, Washington University School of Medicine, 660 South Euclid Avenue, St. Louis, MO 63110.

Present address: Department of Physiology, University of Texas Health Science Center of San Antonio, 7703 Floyd Curl Drive, San Antonio, TX 782847756.

Copyright (c) 1991 Society for Neuroscience $0270-6474 / 91 / 112545-07 \$ 03.00 / 0$
}

1984; Hagberg et al., 1985), and lesioning of glutaminergic excitatory inputs is sparing of hippocampal neurons during ischemia (Johansen et al., 1986; Onodera et al., 1986). Ischemic neuronal degeneration can be attenuated by antagonists of the NMDA subclass of GLU receptors (Simon et al., 1984a; Swan and Meldrum, 1990; but see Lanier et al., 1990). These results have led to the hypothesis that cerebral ischemia leads to the release of toxic concentrations of GLU into the extracellular space with subsequent neuronal injury.

One potential oversight that characterizes most of the in vivo and in vitro experiments on the pathophysiology of hypoxic/ ischemic neuronal injury is the failure to consider how neuronal hypoxia/ischemia might interact with GLU neurotoxicity. It would be reasonable to expect that metabolically compromised neurons might be much more sensitive to the toxic effects of a given GLU concentration.

In view of the recognized link between extracellular calcium and both GLU toxicity (Choi, 1987; Rothman et al., 1987; Hahn et al., 1988) and ischemic damage (Simon et al., 1984b), we decided to investigate how extracellular GLU and metabolic inhibition would interact to influence ionized intracellular calcium $\left(\mathrm{Ca}^{2+}\right)$ and neuronal death in cultured hippocampal neurons. Specifically, we tested the hypothesis that GLU would produce a much larger rise in $\mathrm{Ca}^{2+}{ }_{i}$ in cells treated with sodium cyanide $(\mathrm{NaCN})$ to inhibit oxidative phosphorylation and that GLU would be much more toxic to $\mathrm{NaCN}$-treated neurons.

The outcome of this series of experiments was surprising. While $\mathrm{NaCN}$ did dramatically potentiate the increase in $\mathrm{Ca}^{2+}{ }_{i}$ stimulated by GLU, it had remarkably little effect on eventual neuronal death. In fact, under our experimental conditions, we found no correlation between $\mathrm{Ca}^{2+}{ }_{i}$ and neuronal degeneration.

\section{Materials and Methods}

Cell culture. Dissociated cultures of neonatal rat hippocampus were prepared as previously reported (Yamada et al., 1989; Michaels and Rothman, 1990). These were plated onto collagen- and polylysine-coated substrates: plastic $35-\mathrm{mm}$ Petri dishes for toxicity experiments or glass coverslips glued over holes cut into the bottoms of 35-mm Petri dishes for calcium measurements. In all experiments, cells were used between 14 and $18 \mathrm{~d}$ after plating.

Calcium measurements. Cultures were incubated in $4 \mu \mathrm{M}$ fura-2-AM (lots 9G and 9J, Molecular Probes) added to the growing medium for 45-60 $\mathrm{min}$, rinsed, and allowed to sit for 10-15 $\mathrm{min}$ before measurements were taken on a Nikon Diaphot microscope. In a few experiments, $100 \mu_{\mathrm{M}}$ of the pentapotassium salt of fura-2 $\left(\mathrm{K}_{\mathrm{s}}\right.$ fura-2) was dialyzed into individual cells for $3 \mathrm{~min}$ through a patch electrode containing, in mM, $140 \mathrm{KCl}, 10 \mathrm{NaHEPES}, 4$ glucose, and $2 \mathrm{MgATP}$. Five to ten neurons were loaded before measurements were taken. Cells were continuously perfused at $33-35^{\circ} \mathrm{C}$ with a basic salt solution containing, in $\mathrm{mm}, 140 \mathrm{NaCl}, 3 \mathrm{KCl}, 10 \mathrm{NaHEPES}, 40$ glucose, $1.8 \mathrm{CaCl}_{2}, 0.8 \mathrm{MgCl}_{2}$, and 0.1 glycine. Glycine was omitted in the experiments employing 
7-chlorokynurenic acid. Internal peristaltic-pump tubing volume was 1 $\mathrm{ml}$, total chamber volume was $300 \mu \mathrm{l}$, and perfusion rate was approximately $1 \mathrm{ml} / \mathrm{min}$. Rapid responses to GLU were detected $1 \mathrm{~min}$ after a solution change.

Ratio measurements of fura- 2 fluorescence were made according to established procedures (Grynkiewicz et al., 1985). A stepping motor rotated the $10-\mathrm{nm}$-wide excitation filters centered at 340 and $380 \mathrm{~nm}$ (Oriel) into the light path from a $75-\mathrm{W}$ xenon source. An additional 0.6 ND filter was used with the $380-\mathrm{nm}$ filter. Light passed through a 455 $\mathrm{nm}$ dichroic mirror and a Nikon $40 \times, 1.3-\mathrm{NA}$ epifluorescent objective to reach the cells. Individual cells, usually separated by $25 \mu \mathrm{m}$ from surrounding neurons, were centered in the light path by a sliding diaphragm, and their fluorescence emissions $(515-560 \mathrm{~nm})$ were monitored by a Nikon P1 photomultiplier equipped with a Hamamatsu R1104 photomultiplier tube. In later experiments, a computer-controlled shutter (Uniblitz VS25) was added to the input light path. Photomultiplier output was fed into an analog-to-digital converter (Modular Instruments) and captured by a personal computer using custom software.

A single ratio measurement required $4 \mathrm{sec}$. In most experiments, four consecutive ratios were obtained for a single neuron in a given condition before seeking out the next neuron. Baseline measurements for 10-12 neurons were obtained before perfusing in the test solution. One neuron was monitored during the solution change (about $5 \mathrm{~min}$ ), and then the other previously identified neurons were polled in turn for their responses. Approximately $10 \mathrm{~min}$ were required to relocate all cells in a given experiment.

Background fluorescence values at 340 and $380 \mathrm{~nm}$ were obtained for a neuron-free area of neuropil initially and at the conclusion of an experiment. If these values changed over time, the time-dependent decay was calculated, and appropriately scaled backgrounds were applied for all data points. This correction was unnecessary once the shutter was added to the system. These background values were subtracted from the neuronal $340-$ and $380-\mathrm{nm}$ measurements before calculating 340:380 ratio values $(R)$. Free intracellular calcium concentrations were calculated from the formula $\left.\mathrm{Ca}^{2+}{ }_{i}=K_{d}\left[R-R_{\min }\right) /\left(R_{\max }-R\right)\right]\left(F_{d} / F_{s}\right)$, where $K_{d}=224 \mathrm{nM}$ (Grynkiewicz et al., 1985). $R_{\min }$ and $R_{\max }$, the ratios obtained in the absence of added calcium and in the presence of excess $\mathrm{Ca}^{2+}{ }_{i}$, and $F_{d} / F_{s}$, the ratio of $380-$ nm fluorescence in these two conditions, were determined in two ways. At the end of some experiments, $5 \mu \mathrm{M}$ ionomycin, $20 \mathrm{~mm}$ EGTA, and $12 \mathrm{~mm} \mathrm{MnCl}_{2}$ were added sequentially to the bathing solution, and cells were polled for $R_{\max }, R_{\min }$, and true autofluorescence values after each respective addition. These values were also obtained from fluorescence measurements of solutions containing $4 \mu \mathrm{M} \mathrm{K}$ fura-2, $120 \mathrm{mM} \mathrm{KCl}, 20 \mathrm{~mm} \mathrm{NaCl}, 10 \mathrm{mM} \mathrm{K}-\mathrm{HEPES}$, $10 \mathrm{~mm}$ glucose, and either $10 \mathrm{mM} \mathrm{K}_{2}$ EGTA or $10 \mathrm{mM} \mathrm{CaK}_{2}$ EGTA. The values obtained in ionomycin were lower than those in solution, but in general the two methods agreed. Initially values of $R_{\max }, R_{\min }$, and $F_{\mathrm{o}} /$ $F_{s}$, averaged from all calibrations, were $29,0.8$ and 8.3 , respectively. After realignment of the arc lamp, they became $24,0.8$, and 7.6 . In order to compare experiments, all $R$ values were translated to $\mathrm{Ca}^{2+}$ values before calculating the changes in $\mathrm{Ca}^{2+}$, reported here.

Toxicity. We compared the neurotoxicity of GLU and $\mathrm{NaCN}$ on a separate set of hippocampal cultures. Culture medium was replaced with the same physiological buffer used in the $\mathrm{Ca}^{2+}{ }_{i}$ determinations. The appropriate concentrations of $\mathrm{GLU}, \mathrm{NaCN}$, or a combination of the two were then added to culture dishes, which were subsequently placed into a $37^{\circ} \mathrm{C}$ incubator for 10 or $30 \mathrm{~min}$. Cultures were then washed three times with Minimal Essential Medium (MEM; Earle's salts) containing $500 \mathrm{mg} \%$ glucose.

The cultures were kept in MEM and returned to a $5 \% \mathrm{CO}_{2}, 37^{\circ} \mathrm{C}$ incubator for $18 \mathrm{hr}$. At that time, trypan blue (4\% final concentration) was added for $5 \mathrm{~min}$, followed by two washes with Earle's balanced salt solution. We then counted the number of stained and unstained neurons in two previously scored portions of the culture dish, each about $1 \mathrm{~mm}^{2}$. The percent unstained neurons indicated our percent viability (Michaels and Rothman, 1990). At least four dishes (two fields/dish) were used for each GLU or $\mathrm{NaCN}$ concentration. Because neurons in our cultures sit above a glial monolayer, we have little difficulty identifying them unambiguously. Extensive experience with intracellular recording has demonstrated that phase-bright, process-bearing cells invariably have the physiological properties of neurons (Yamada et al., 1989).

Chemicals. Fura-2-AM, $\mathrm{K}_{5}$ fura-2, and ionomycin were obtained from Molecular Probes. Merck, Sharp and Dohme and Norwich Eaton gave us the methyl-10,11-dihydro-5-H-dibenzocyclohepten-5,10-imine (MK801 ) and dantrolene, respectively. We bought 6-cyano-7-nitroquinox- aline-2,3-dione (CNQX) and 7-chlorokynurenic acid from Tocris Neuramin. All other chemicals were obtained from Sigma.

\section{Results}

Intracellular calcium measurements. Resting $\mathrm{Ca}^{2+}{ }_{i}$ for cultured hippocampal neurons ranged from 50 to 130 nM. Small oscillations were evident in many neurons, but the periodicity was not determined. Neurons responded to GILU with a rapid initial transient increase in intracellular calcium, which declined to an elevated steady-state level (Murphy and Miller, 1989a; Glaum et al., 1990). This transient increase was often too fast to define completely on our system. The $\mathrm{Ca}^{2+}{ }_{i}$ remained elevated over 30-40 min, even after GLU removal and extensive rinsing. Considerable variation among neurons in the same culture was observed. Fluorescence ratios for steady-state hippocampal neuronal responses to increasing concentrations of GLU are presented in Figure $1 A$.

Responses to GLU became readily detectable at $3 \mu \mathrm{M}$ and maximized above $300 \mu \mathrm{M}$. When we fit our data with the logistic equation

$$
\mathrm{Ca}^{2+}{ }_{i}=\mathrm{Ca}^{2+}{ }_{i \max } /\left(1+\left(\mathrm{EC}_{50} /[\mathrm{GLU}]\right)^{n}\right)
$$

and allowed the three constant parameters to vary, we obtained a concentration-response curve with an $\mathrm{EC}_{50}$ for GLU of $30 \mu \mathrm{M}$ and a Hill coefficient of 1 . The maximum change in $\mathrm{Ca}^{2+}{ }_{i}$ was $263 \mathrm{~nm}$.

Because we were interested in determining how hypoxia/ischemia altered the $\mathrm{Ca}^{2+}$ increase triggered by GLU, we first had to examine the effect of these insults alone on $\mathrm{Ca}^{21}{ }_{i}$. We used $\mathrm{NaCN}$ as a model of chemical hypoxia (Rothman, 1983; Goldberg et al., 1987) and measured $\mathrm{Ca}^{2+}{ }_{i}$ over a range of $\mathrm{NaCN}$ concentrations (Fig. $1 B$ ). Hippocampal neurons responded more slowly to $\mathrm{NaCN}$, requiring up to $5 \mathrm{~min}$ of exposure to increase $\mathrm{Ca}^{2+}{ }_{i}$ to steady-state levels. For $\mathrm{NaCN}$ applications of less than $15 \mathrm{~min}$, this rise reversed within $5 \mathrm{~min}$ when cyanide was removed from the perfusate. The threshold concentration of $\mathrm{NaCN}$ that produced a rise in $\mathrm{Ca}^{2+}{ }_{i}$ was $100 \mu \mathrm{M}$; in the presence of 3$10 \mathrm{~mm} \mathrm{NaCN}, \mathrm{Ca}^{2+}{ }_{i}$ reached micromolar concentrations, four to five times the maximum observed at the highest GLU concentrations.

We went on to determine how $\mathrm{NaCN}$ influenced our initial GLU concentration-response curve. We reasoned that metabolic inhibition produced by $\mathrm{NaCN}$ might magnify the GLUinduced $\mathrm{Ca}^{2+}{ }_{i}$ increases. In these experiments, $300 \mu \mathrm{M} \mathrm{NaCN}$, which is just above the threshold concentration for producing a detectable rise in $\mathrm{Ca}^{2+}{ }_{i}$, was combined with increasing concentrations of GLU. When the $\mathrm{Ca}^{2+}$, values obtained in these experiments were fit to the same logistic equation used for GLU alone, we obtained an $\mathrm{EC}_{50}$ of $7.3 \mu \mathrm{M}$ and a maximum change in $\mathrm{Ca}^{2+}{ }_{i}$ of $400 \mathrm{~nm}$ (Fig. $1 A$ ). While $\mathrm{NaCN}$ changed the GLU concentration-response curve in a complicated way, the additional elevation in $\mathrm{Ca}^{2+}$, over a range of GLU concentrations could be almost completely accounted for by the contribution of the $\mathrm{NaCN}$ alone, about $150 \mathrm{nM}$. These experiments therefore failed to demonstrate any substantial potentiation of GLU-induced $\mathrm{Ca}^{2+}{ }_{i}$ increase by $\mathrm{NaCN}$.

However, analysis of experiments examining the increase in $\mathrm{Ca}^{2+}$, produced by high $\mathrm{NaCN}$ concentrations altered this conclusion. We found that the $\mathrm{Ca}^{2+}{ }_{i}$ rise associated with $3 \mathrm{~mm}$ $\mathrm{NaCN}$ was markedly attenuated by two NMDA antagonists, MK-801 and 7-chlorokynurenic acid (Kemp et al., 1988). In addition, these two compounds reduced the $\mathrm{Ca}^{2+}{ }_{i}$ rise seen after 

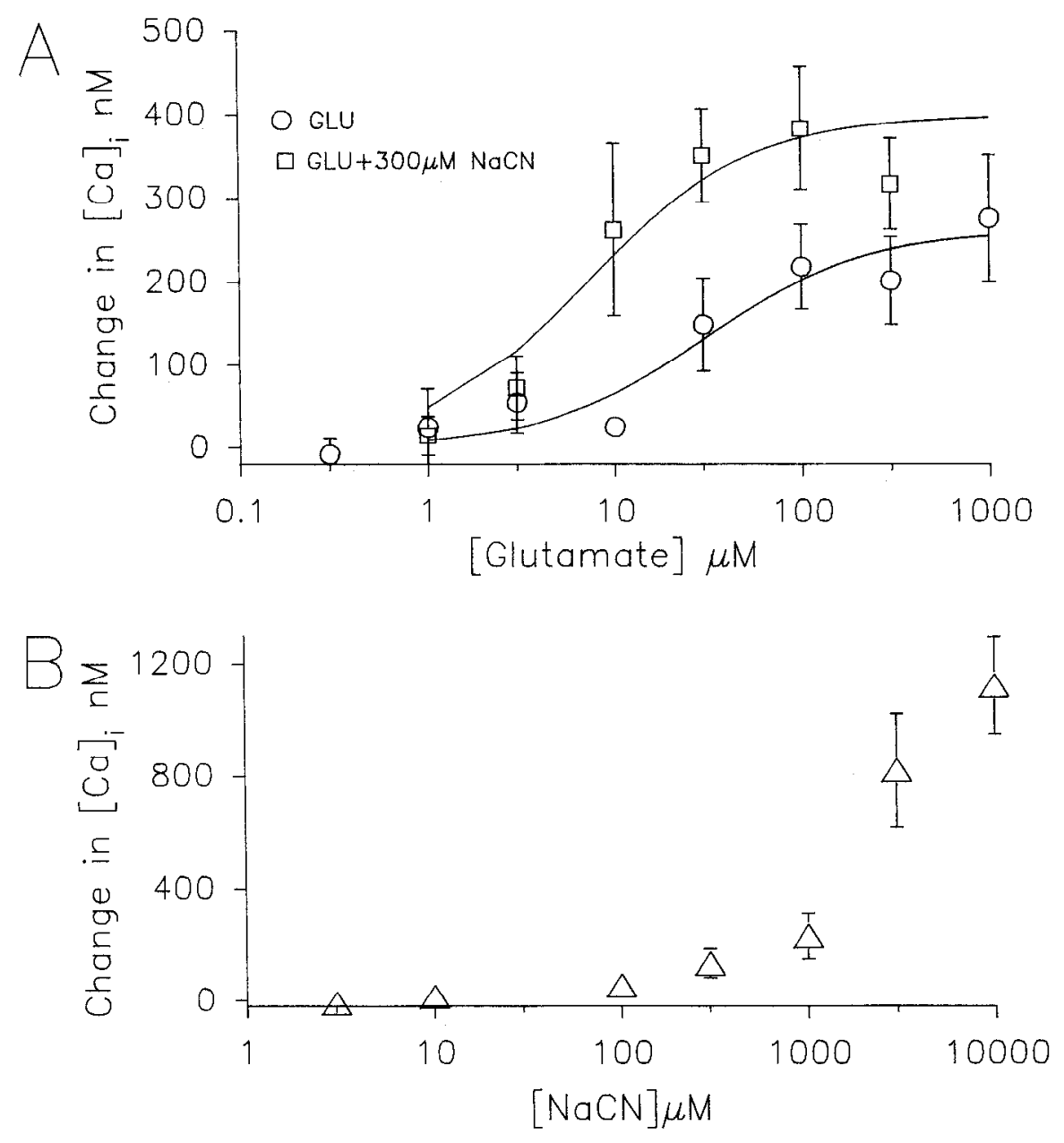

Figure 1. Increases in intracellular calcium produced by various concentrations of GLU or $\mathrm{NaCN}$. $A$, Concentration-response curves for GLU alone and in the presence of $300 \mu \mathrm{M} \mathrm{NaCN}$. The smooth curves were fit to a logistic equation described in the text. (The data point at $300 \mu \mathrm{M} G L U$ was not used in fitting the upper curve.) $B$, Concentration-response curves for increasing levels of $\mathrm{NaCN}$ begin to show a rise at 100 $\mu \mathrm{M}$ but still have not reached maximum at $10 \mathrm{~mm}$. In both $A$ and $B$, each point represents mean \pm SEM for 10-30 individual cells.

GLU exposure (Fig. $2 A$ ). The effect on the $\mathrm{NaCN}$-induced $\mathrm{Ca}^{2+}{ }_{i}$ rise is especially significant because the reductions produced by MK-801 or 7-chlorokynurenic acid are approximately $700 \mathrm{nM}$, more than double the maximum rise in $\mathrm{Ca}^{2+}$ produced by the highest concentration of GLU alone. CNQX, a non-NMDA receptor antagonist (Yamada et al., 1989), was less effective at blocking $\mathrm{NaCN}$-induced calcium rises. Interestingly, the calcium response stimulated by combined, submaximal doses of GLU and $\mathrm{NaCN}$ was not altered by MK-801 alone, but was markedly attenuated by combined CNQX and MK-801 (Fig. $2 B$ ).

The involvement of GLU receptor-linked calcium influx in "chemical hypoxia" implies that endogenous GLU may accumulate extracellularly after insults to neuronal metabolism. Although perfusion rates were high, such accumulation may act locally before glial uptake or washout. In an attempt to support this hypothesis, we added the enzyme glutamate-pyruvate transaminase (GPT; $25 \mathrm{U} / \mathrm{ml})$ and pyruvate $(10 \mathrm{~mm})$ to try to accelerate the breakdown of GLU during GLU and NaCN challenges (Fig. $2 A$ ). This enzymatic degradation of GLU to $\alpha$-ketoglutarate blocked increases in $\mathrm{Ca}^{2+}{ }_{i}$, though not as effectively as the NMDA antagonists. Nonetheless, the result is consistent with $\mathrm{NaCN}$-induced $\mathrm{Ca}^{2+}{ }_{i}$ rises caused by extracellular accumulation of endogenous GLU. Thus, the combination of $\mathrm{NaCN}$ and the cndogenous GLU increased $\mathrm{Ca}^{2+}$ far in excess of either agent alone.
Source of calcium. The striking observation in the above experiments is that $\mathrm{NaCN}$ causes $\mathrm{Ca}^{2+}{ }_{i}$ to rise much higher than high concentrations of GLU alone, yet these increases are almost completely eliminated by antagonists of GLU receptors. The following experiments focus on the source of this calcium increase.

We first had to verify that the greatly elevated $\mathrm{Ca}^{2+}{ }_{i}$ seen with $\mathrm{NaCN}$ reflected calcium in the cytoplasmic compartment, because intracellular compartments other than the cytoplasm could be loaded with fura-2-AM. To test this possibility, cells were directly loaded with $\mathrm{K}_{5}$ fura-2 during intracellular recording with patch pipettes in the whole-cell configuration. In this condition, $3 \mathrm{~mm} \mathrm{NaCN}$ produced $R=3.68 \pm 0.64$ (mean $\pm \mathrm{SEM} ; N=$ 6 ), and $300 \mu \mathrm{M}$ GLU produced $R=2.33 \pm 0.21(N=8)$. Because ratio values for ionomycin calibrations of $\mathrm{K}_{5}$ fura-2-loaded cells were depressed compared to fura-2-AM-loaded cells, absolute calcium levels were not calculated in these experiments. However, the higher $R$ seen with $\mathrm{NaCN}$ compared to GLU indicates that the cytoplasmic calcium compartment is the one altered by $\mathrm{NaCN}$.

Elevations of $\mathrm{Ca}^{2+}{ }_{i}$ produced by elevated external potassium $\left(\mathrm{K}^{+}{ }_{o}\right)$ were examined to determine if depolarization-induced influx produced steady-state calcium levels as high as $\mathrm{NaCN}$. Instead, $\mathrm{K}^{+}{ }_{0}$-induced increases in $\mathrm{Ca}^{2+}{ }_{i}$ resembled GLU induced levels (Fig. 3), though these were not blocked by MK-801 (changc in $\mathrm{Ca}^{2+}{ }_{i}, 171 \pm 79 \mathrm{nM} ; N=12$ ). 


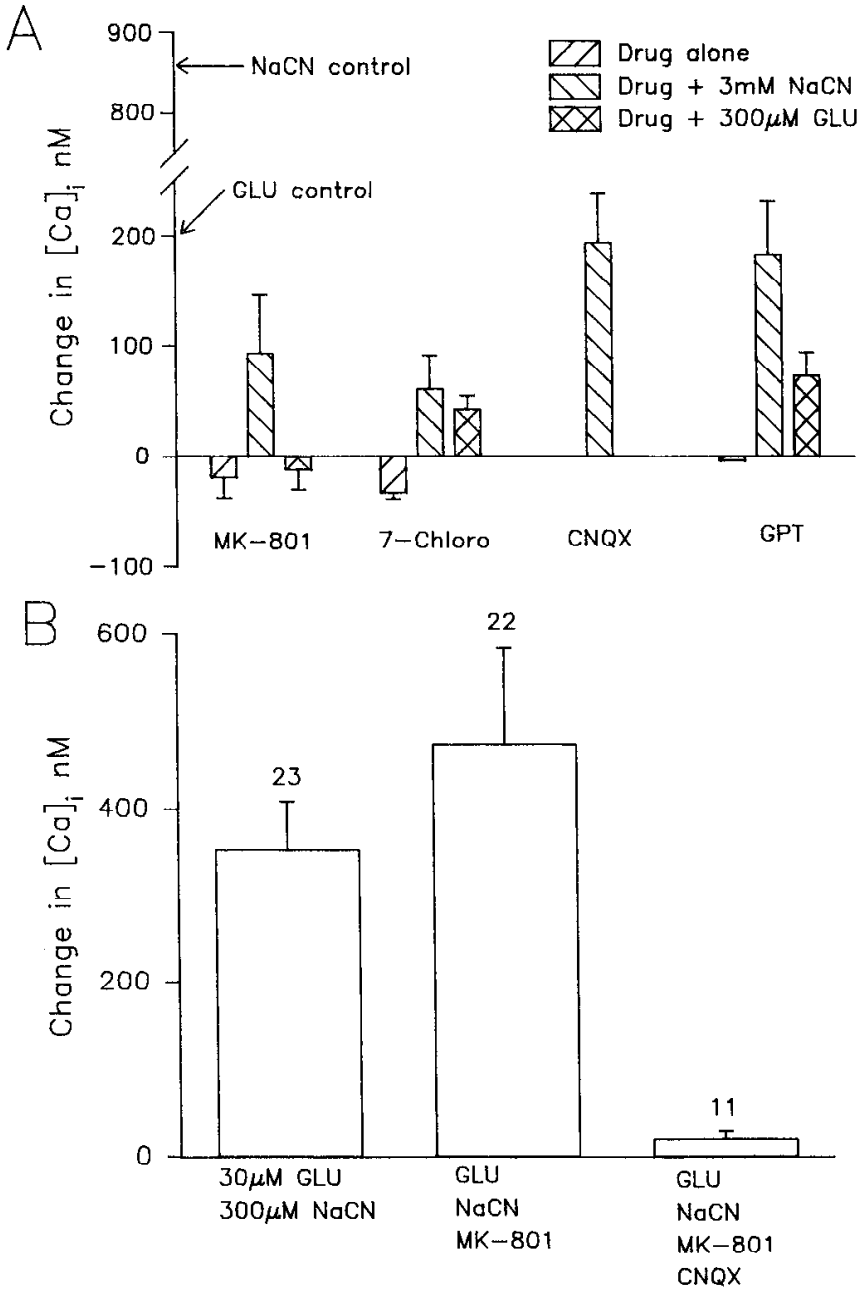

Figure 2. GLU receptor antagonists prevent rises in $\mathrm{Ca}^{2+}{ }_{i} . A$, The NMDA antagonists MK-801 $(20 \mu \mathrm{M})$ and 7-chlorokynurenic acid (7Chloro; $30 \mu \mathrm{M})$ dramatically reduced the $\mathrm{Ca}^{2+}{ }_{i}$ increase associated with $\mathrm{NaCN}(3 \mathrm{~mm})$ or GLU $(300 \mu \mathrm{M})$. CNQX $(20 \mu \mathrm{M})$ was less effective in reducing $\mathrm{Ca}^{2+}{ }_{i}$ after $\mathrm{NaCN}$ exposure. Enzymatic degradation of GLU by GPT also diminished $\mathrm{Ca}^{2+}{ }_{2}$. The arrows adjacent to the ordinate indicate the $\mathrm{Ca}^{2+}{ }_{i}$ values with $\mathrm{NaCN}$ or GLU alone taken from Figure 1. $B$, MK-801 $(20 \mu \mathrm{M})$ did not block the $\mathrm{Ca}^{2+}{ }_{i}$ signal caused by combined exposure to GLU $(30 \mu \mathrm{M})$ and $\mathrm{NaCN}(300 \mu \mathrm{M})$. However, addition of CNQX $(20 \mu \mathrm{M})$ did normalize $\mathrm{Ca}^{2+}{ }_{i}$. Numbers over error bars are number of measurements. Error bars on both $A$ and $B$ represent SEM.

To verify that the additional free calcium liberated by $\mathrm{NaCN}$ was dependent upon calcium entry from the extracellular space, we mcasured $\mathrm{Ca}^{2+}{ }_{i}$ during challenges in bathing solutions with no added calcium (Fig. 3). Under these conditions, the external calcium concentration was estimated to be about $15 \mu \mathrm{M}$ (Rothman, 1985). Hippocampal neurons did not survive when external calcium $\left(\mathrm{Ca}^{2+}{ }_{0}\right)$ was further reduced with chelators. In the absence of added $\mathrm{Ca}^{2+}{ }_{o}$, baseline internal calcium levels decreased about $20 \mathrm{nM}$, and steady-state responses to GLU and high $\mathrm{K}^{\prime}$ were reduced. $\mathrm{NaCN}$ continued to raise $\mathrm{Ca}^{2+}{ }_{i}$ to a greater extent than the other treatments, but the $\mathrm{NaCN}$-induced rise in $\mathrm{Ca}^{2+}{ }_{i}$ was itself dramatically lower than in normal external calcium. Thus, the $\mathrm{NaCN}$-induced increase in $\mathrm{Ca}^{2+}{ }_{i}$ was partially dependent upon $\mathrm{Ca}^{2+}{ }_{o}$, but also required some intracellular amplification.

To clarify the contribution of calcium from internal sources to the $\mathrm{NaCN}$ response, GLU and $\mathrm{NaCN}$ challenges were performed in the presence of other types of metabolic inhibitors (Fig. 4). Dantrolene, which blocks release of $\mathrm{Ca}^{2+}$ from sarcoplasmic reticulum in muscle (SR; Van Winkle, 1976), and ruthenium red, which blocks mitochondrial uptake of $\mathrm{Ca}^{2+}$ and $\mathrm{Ca}^{2+}$-stimulated $\mathrm{Ca}^{2+}$ release from SR (Reed and Bygrave, 1974; Smith et al., 1985), both abolished the $\mathrm{NaCN}$-induced rises in $\mathrm{Ca}^{2+}$, while having little effect on GLU responses. Thus, intracellular stores of calcium contributed significantly to the rise in $\mathrm{Ca}^{2+}{ }_{i}$ and possibly to the process leading to the accumulation of extracellular GLU. Oligomycin and 2,4-dinitrophenol, respectively an inhibitor and uncoupler of oxidative phosphorylation (Lehninger, 1975), produced larger rises in $\mathrm{Ca}^{2+}$, than GLU, though these took much longer to develop. The response to oligomycin was also blocked by the combination of $20 \mu \mathrm{M}$ MK-801 and $20 \mu \mathrm{M}$ CNQX (change in $\mathrm{Ca}^{2+}, 13 \pm 42 \mathrm{nM} ; N=$ 14). Sodium azide, a blocker of cytochrome $\mathrm{a}_{3}$ action, like $\mathrm{NaCN}$ (Keilin and Hartree, 1939), produced large steady-state $\mathrm{Ca}^{2+}{ }_{i}$ levels comparable to $\mathrm{NaCN}$. Caffeine, which stimulates release of calcium from a nonmitochondrial intracellular pool in sympathetic neurons (Thayer et al., 1988), was virtually ineffective at producing steady-state rises in intracellular calcium in hippocampal neurons (change in $\mathrm{Ca}^{2+}{ }_{i},-7 \pm 5 \mathrm{nM} ; N=11$ ), even after prior application of high $\mathrm{K}^{+}{ }_{o}$ (change in $\mathrm{Ca}^{2+}, 30 \pm 8 \mathrm{nM}$; $N=22$ ).

Neurotoxicity. If rises in intracellular calcium are indicative of the toxicity of a treatment, then the NaCN model of "chemical hypoxia" should be extremely neurotoxic. Surprisingly, long exposures to $3 \mathrm{~mm} \mathrm{NaCN}$ produced no change in cell viability (Fig. 5A). When combined with toxic doses of GLU, $3 \mathrm{~mm}$ $\mathrm{NaCN}$ did not increase neuronal death beyond that produced by GLU alone (Fig. $5 B$ ). However, $3 \mathrm{~mm} \mathrm{NaCN}$ did slightly potentiate the toxicity of a very low concentration of GLU (Fig. $5 C)$.

\section{Discussion}

We believe that there are two important conclusions from this set of experiments: (1) in the presence of sufficient metabolic inhibition, GLU can produce enormous increases in $\mathrm{Ca}^{2+}{ }_{i}$, far beyond those observed when intermediary metabolism is intact; and (2) high $\mathrm{Ca}^{2+}{ }_{i}$ immediately after an insult does not necessarily indicate cell death when oxidative metabolism is blocked.

The mechanism(s) by which $\mathrm{NaCN}$ elevates $\mathrm{Ca}^{2+}{ }_{i}$ has not been completely elucidated by our experiments. Direct release of sequestered intracellular calcium, as occurs in squid axon (Baker et al., 1971), cannot fully explain our results because GLU receptor antagonists greatly diminish the response. We suspect that metabolic blockade produced a small elevation in cxtraccllular GLU by incrcasing its lcakagc, stimulating relcasc, or disrupting reuptake (Silverstein et al., 1986). This GLU caused a flux of calcium into neurons that was not buffered by normal cellular sequestration processes and triggered the secondary release of calcium from intracellular stores. The combination of these two factors led to an enormous increase in $\mathrm{Ca}^{2+}{ }_{i}$. The ability of both dantrolene and ruthenium red to limit $\mathrm{NaCN}$ induced $\mathrm{Ca}^{21}{ }_{i}$ increases supports the hypothesis that this $\mathrm{Ca}^{2}{ }_{i}$ is derived from intracellular stores. They both fail to reduce GLU-induced rises in $\mathrm{Ca}^{2+}{ }_{i}$, consistent with an extracellular origin for this $\mathrm{Ca}^{2+}$.

We suspect that the GLU concentration in the presence of 3 $\mathrm{mM} \mathrm{NaCN}$ is less than $30 \mu \mathrm{M}$, because MK-801 almost normalized the $\mathrm{Ca}^{2+}$ in the presence of $3 \mathrm{~mm} \mathrm{NaCN}$, but failed to 


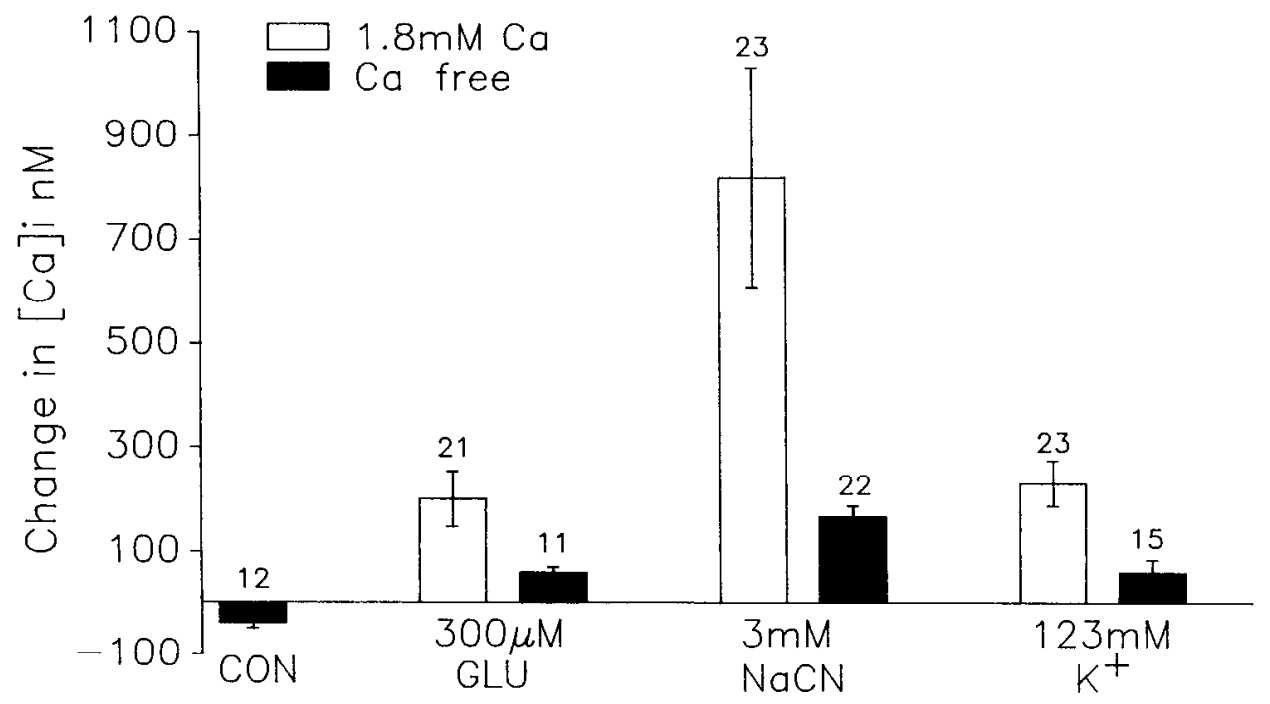

Figure 3. Changes in $\mathrm{Ca}^{2+}$ encountered in normal bathing solution and in bathing solution with no added calcium during exposure to $300 \mu \mathrm{M}$ GLU, $3 \mathrm{~mm}$ $\mathrm{NaCN}$, and $123 \mathrm{~mm} \mathrm{~K}^{+}$. CON, control. reduce $\mathrm{Ca}^{2+}{ }_{i}$ when $30 \mu \mathrm{M}$ GLU and $300 \mu \mathrm{M}$ NaCN were combined. We altempled to document the rise in extracellular GLU by direct biochemical analysis but were unable to detect differences in control and $\mathrm{NaCN}$-treated cultures because the GLU
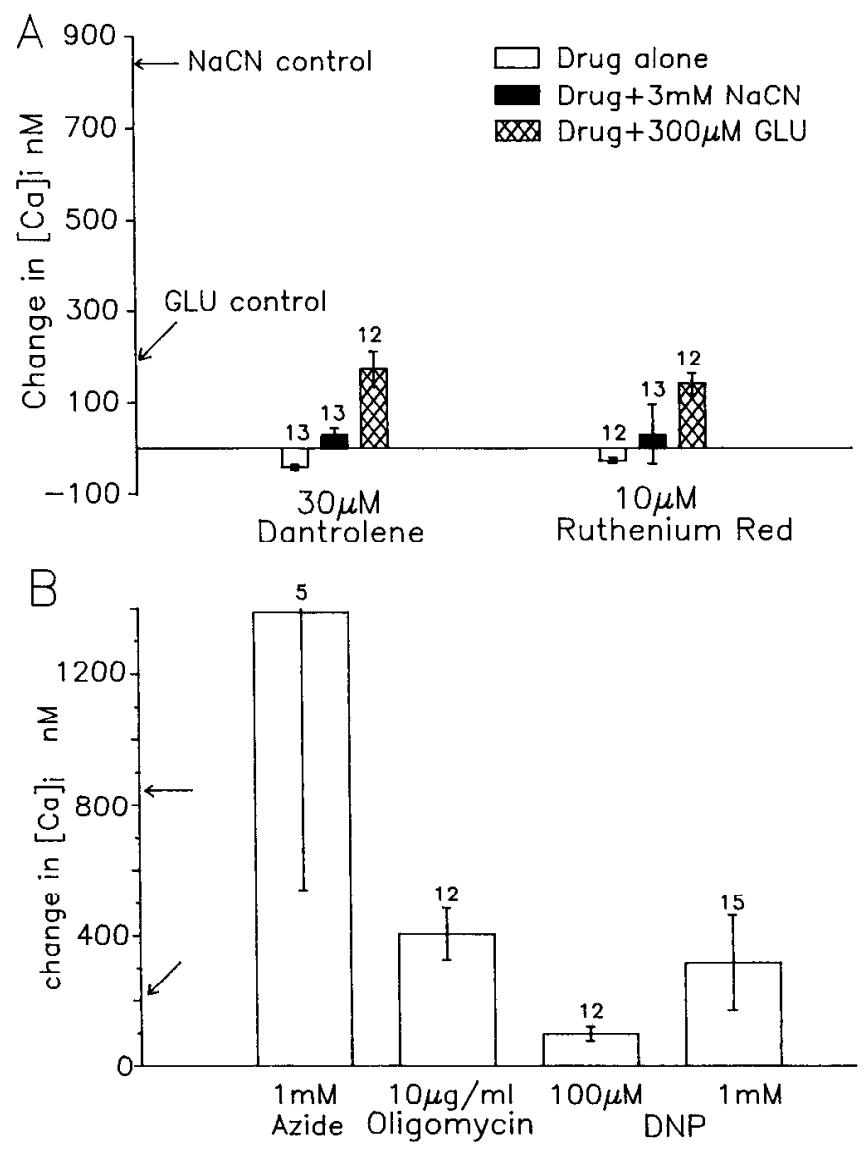

Figure 4. A, Inhibitors of $\mathrm{Ca}^{2+}$ release from intracellular pools prevent $\mathrm{NaCN}$-induced increases in $\mathrm{Ca}^{2+}{ }_{i}$ but do not alter GLU-induced calcium changes. $B$, Other inhibitors of intermediary metabolism greatly increase intracellular calcium. Responses are shown for $1 \mathrm{~mm}$ sodium azide, 10 $\mu \mathrm{g} / \mathrm{ml}$ oligomycin, and both $100 \mu \mathrm{M}$ and $1 \mathrm{~mm}$ 2,4-dinitrophenol (DNP). Note change in vertical scale. Arrows indicate changes induced by $\mathrm{NaCN}$ and GLU alone as shown in Figure 1. elevation was probably restricted to a region close to the cellular layer in our culture dishes.

We have been intrigued by the lack of $\mathrm{NaCN}$ toxicity despite the enormous sustained magnitude of $\mathrm{Ca}^{2+}{ }_{i}$ in these experiments. There is now a widely accepted body of scientific literature linking elevated $\mathrm{Ca}^{2+}{ }_{i}$ with cellular injury and death (Schanne et al., 1979; Orrenius et al., 1989; Siesjö, 1989). In cultured central neurons, there is a clear requirement for extracellular calcium in the process leading to neuronal death secondary to GLU toxicity (Choi, 1987, 1990; Rothman et al., 1987; Hahn ct al., 1988). Our results, however, are consistent with observations in at least two other systems. Hypoxic rat cardiac myocytes do not elevate $\mathrm{Ca}^{2+}{ }_{\text {i }}$ prior to death (Cheung et al., 1986), and "chemically anoxic" cultured hepatocytes fail to show an abnormal $\mathrm{Ca}^{2+}{ }_{i}$ immediately prior to blebbing and subsequent death (Lemasters et al., 1987). There are even situations in neuronal development in which elevations in $\mathrm{Ca}^{2+}$, are beneficial for cell survival (Gallo et al., 1987; Collins and Lile, 1989; Koike et al., 1989). The current results also agree with our own previous experience suggesting a poor correlation between $\mathrm{Ca}^{2+}{ }_{i}$ and cell death (Michaels and Rothman, 1990).

The explanation for our neurons' survival with extremely high $\mathrm{Ca}^{2+}{ }_{i}$ is complex, depending upon a number of factors. First, the $\mathrm{Ca}^{2+}{ }_{i}$ elevation may not have occurred in a "sensitive compartment." Both Connor et al. (1988) and Simon and Llinas (1985) have shown that calcium may be sequestered in different cellular compartments. During this study, we restricted our measurements to neuronal cell bodies. The critical increase in $\mathrm{Ca}^{2+}{ }_{i}$ responsible for cell death may take place in more distal dendrites that are inaccessible to our photometer. Future experiments employing cell-imaging techniques will be required to address this question. Second, even within the cell body, many of the calcium-regulated processes linked to cell injury (Orrenius et al., 1989) may not be activated by calcium released from intracellular stores. They may be physically linked to the cell membrane and only turned on by calcium actually translocated across the plasma membrane. Until the cascade of events responsible for cell death is understood in detail, it will be difficult to resolve this issue. Nevertheless, it should not be so surprising that the biological effects of elevated $\mathrm{Ca}^{2+}{ }_{i}$ differ, depending upon whether the calcium is derived from an intracellular or extracellular source. Kim and Westhead (1989) have recently shown that 

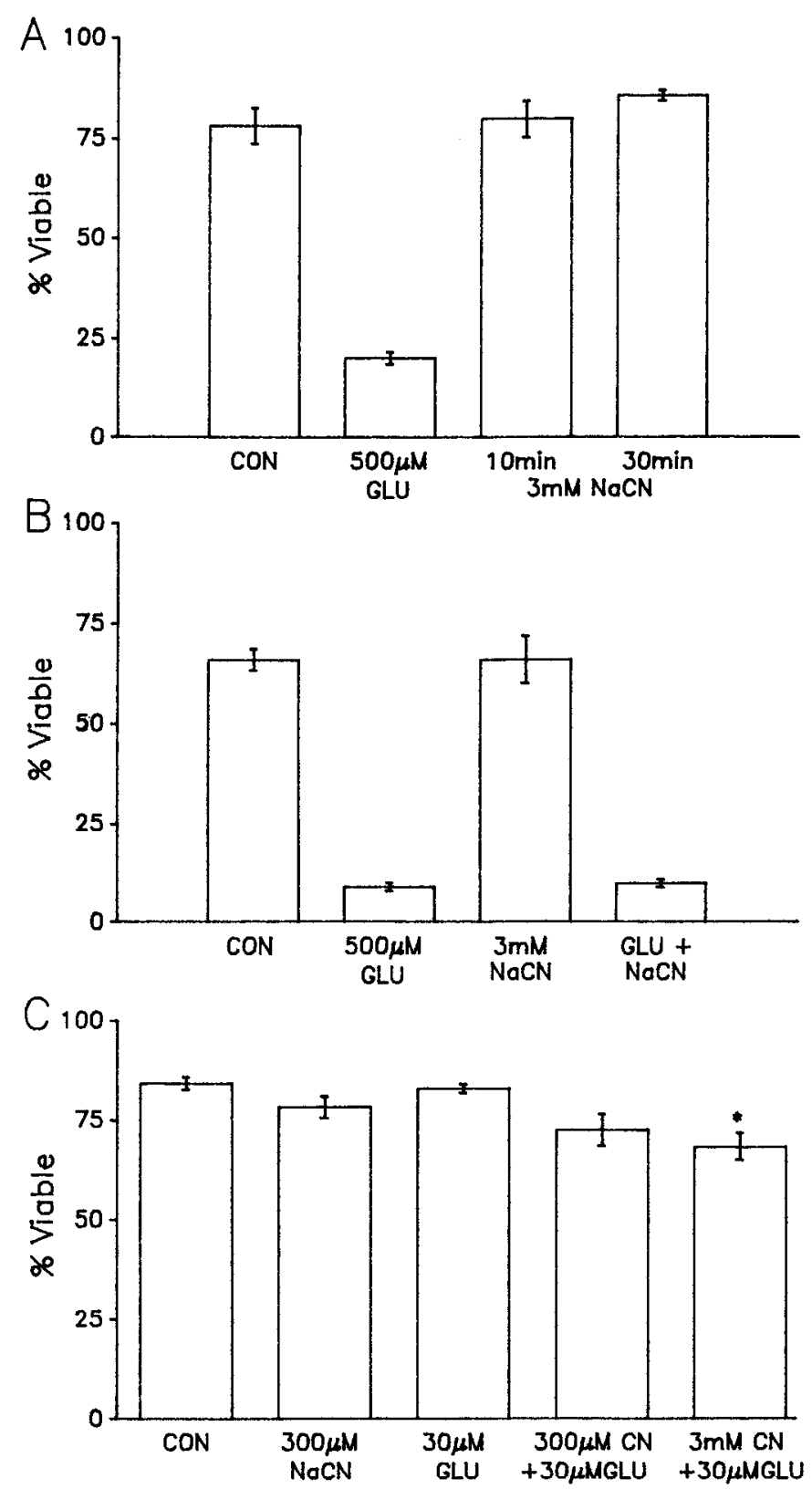

Figure 5. Survival of hippocampal neurons exposed to combined GLU and $\mathrm{NaCN}$ insults. $A$, Percentage of neuronal population surviving after $10 \mathrm{~min}$ exposure to GLU, or 10 or $30 \mathrm{~min}$ exposure to $\mathrm{NaCN} ; N=10$ for each condition. $B$, A high dose of $\mathrm{NaCN}$ did not increase the toxicity of a maximally toxic dose of GLU $(10 \mathrm{~min} ; N=8) . C, \mathrm{NaCN}$ had little effect on the neurotoxicity of sublethal concentrations of GLU. Only the highest concentration of $\mathrm{NaCN}(3 \mathrm{~mm})$ slightly potentiated the toxicity of $30 \mu \mathrm{M}$ GLU after a 5 -min exposure $(N=12) .^{*}, p<0.01$ by ANOVA followed by Newman-Keuls test. CON, control.

chromaffin cell secretion is coupled to $\mathrm{Ca}^{2+}{ }_{i}$ in a complex way, such that increases in $\mathrm{Ca}^{2+}{ }_{i}$ originating from extracellular pools are more effective in triggering transmitter release.

While we measured $\mathrm{Ca}^{2}{ }_{i}$ on a relatively slow time scale and would miss the rapid GLU-induced oscillations described by Murphy and Miller $(1988,1989 \mathrm{~b})$, we doubt that would influence the main conclusions of this article. These rapid oscillations are due to activation of a quisqualate receptor and unlikely to play a major role in cell death because GLU toxicity in cortical and hippocampal cultures is largely mediated by NMDA re- ceptors (Choi et al., 1988; Michaels and Rothman, 1990). In fact, exposure of our neurons to GLU for up to $2 \mathrm{hr}$ in the presence of MK-801 leads to neuronal swelling but little death, arguing that we previously overestimated the contribution of non-NMDA receptors and neuronal swelling to cell death (Rothman, 1985; Michaels and Rothman, 1990).

Other aspects of this study require comment. We found that the noncompetitive NMDA antagonist MK-801 blocked the $\mathrm{Ca}^{2+}{ }_{i}$ rise produced by either $3 \mathrm{mM} \mathrm{NaCN}$ or $300 \mu \mathrm{M}$ GLU but failed to block the rise induced by the combination of $300 \mu \mathrm{M}$ $\mathrm{NaCN}$ and $30 \mu \mathrm{M}$ GLU. We suspect that in the presence of $\mathrm{NaCN}$ and MK-801 the neurons were unable to buffer the $\mathrm{Ca}^{2+}{ }_{i}$ increase produced by activation of non-NMDA receptors by 30 $\mu \mathrm{M}$ GLU (Murphy and Miller, 1988, 1989a,b). The addition of CNQX to the MK-801 then blocked all receptors and prevented a rise in $\mathrm{Ca}^{2+}{ }_{i}$. In the presence of MK-801 but no $\mathrm{NaCN}, \mathrm{CNQX}$ was not needed to block the GLU-induced $\mathrm{Ca}^{2+}{ }_{i}$ increase because the normal celluiar buffers could handle the calcium load from non-NMDA receptor stimulation.

There may also be some concern that the severe metabolic block produced by $\mathrm{NaCN}$ in some way protected our neurons from the deleterious effects of elevated $\mathrm{Ca}^{2+}{ }_{i}$. We believe that this is unlikely because $\mathrm{NaCN}$ did not prevent GLU toxicity in the combined GLU-NaCN exposures. Using different preparations and paradigms, other investigators have been able to show potentiation of GLU toxicity by metabolic inhibition (Novelli et al., 1988; Kohmura et al., 1990). The underlying pathophysiology of neuronal death may be very different in these systems. The failure of $\mathrm{NaCN}$ to kill our hippocampal neurons differs from the result of an earlier study (Rothman, 1983). A likely reason for this discrepancy is that our culture methods have changed markedly and we now use media with much extracellular GLU and aspartate. This makes less serum and much lower neurons less sensitive to GLU (Sugiyama et al., 1989; Erdo et al., 1990). Our neurons are still killed by GLU, but the lethal concentration has increased.

These limited speculations should not detract from our solid observations that metabolic inhibition leads to a much greater increase in $\mathrm{Ca}^{2+}{ }_{i}$ than seen with GLU but that these increases fail to lead to neuronal death. They emphasize the complicated nature of intracellular calcium homeostasis and the need for more refined information on exactly how calcium entry into cells is linked to cell death.

\section{References}

Baker PF, Hodgkin AL, Ridgeway EB (1971) Depolarization and calcium entry in squid giant axons. J Physiol (Lond) 218:709-755.

Benveniste H, Drejer J, Schousboe A, Diemer NH (1984) Elevation of the extracellular concentrations of GLU and aspartate in rat hippocampus during transient cerebral ischemia monitored by intracerebral microdialysis. J Neurochem 43:1369-1374.

Cheung JY, Leaf A, Bonventre J (1986) Mitochondrial function and intracellular calcium in anoxic cardiac myocytes. Am J Physiol 250: C18-C25.

Choi DW (1987) Ionic dependence of glutamate neurotoxicity in cortical cell culture. J Neurosci 7:369-379.

Choi DW (1990) Cerebral hypoxia: some new approaches and unanswered questions. J Neurosci 10:2493-2501.

Choi DW, Rothman SM (1990) The role of GLU neurotoxicity in hypoxic-ischemic neuronal death. Annu Rev Neurosci 13:171-182.

Choi DW, Koh J-Y, Peters S (1988) Pharmacology of glutamate neurotoxicity in cortical cell culture: attenuation by NMDA antagonists. J Neurosci 8:185-196.

Collins F, Lile JD (1989) The role of dihydropyridine-sensitive volt- 
age-gated calcium channels in potassium-mediated neuronal survival. Brain Res 502:99-108.

Connor JA, Wadman WJ, Hockberger PE, Wong RKS (1988) Sustained dendritic gradients of $\mathrm{Ca}^{2+}$ induced by excitatory amino acids in CA1 hippocampal neurons. Science 240:649-653.

Erdo SL, Michler A, Wolff JR, Tytko H (1990) Lack of excitotoxic ccll dcath in scrum-free cultures of rat cerebral cortex. Brain Res 526: 328-332.

Gallo V, Kingsbury A, Balazs R, Jorgensen OJ (1987) The role of depolarization in the survival and differentiation of cerebellar granule cells in culture. $\mathrm{J}$ Neurosci 7:2203-2213.

Glaum SR, Scholz WK, Miller RJ (1990) Acute- and long-term glutamate-mediated regulation of $\left[\mathrm{Ca}^{++}\right]_{i}$ in rat hippocampal pyramidal neurons in vitro. J Pharmacol Exp Ther 253:1293-1302.

Goldberg MP, Weiss JW, Pham PC, Choi DW (1987) $N$-methyl-Daspartate receptors mediate hypoxic neuronal injury in cortical culture. J Pharmacol Exp Ther 243:784-791.

Grynkiewicz G, Poenie M, Tsien RY (1985) A new generation of $\mathrm{Ca}^{2+}$ indicators with greatly improved fluorescence properties. J Biol Chem 260:3440-3450.

Hagbcrg H, Lchmann A, Sandberg M, Nystrom B, Jacobson I, Hamberger A (1985) Ischemia-induced shift of inhibitory and excitatory amino acids from intra- to extracellular compartments. J Cereb Blood Flow Metab 5:413-419.

Hahn JS, Aizenman E, Lipton S (1988) Central mammalian neurons normally resistant to glutamate toxicity are made sensitive by elevated $\mathrm{Ca}^{2+}{ }_{i}$ : toxicity is blocked by $N$-methyl-D-aspartate antagonist MK801. Proc Natl Acad Sci USA 85:6556-6560.

Johansen FF, Jorgensen MB, Diemer NH (1986) Ischemic CA1 pyramidal cell loss is prevented by preischemic colchicine destruction of dentate gyrus granule cells. Brain Res 377:344-347.

Keilin D, Hartree EF (1939) Cytochrome and cytochrome oxidase. Proc R Soc Lond [Biol] 127:167-191.

Kemp JA, Foster AC, Leesom PD, Priestley T, Tridgett R, Iverson LL, Woodruff GN (1988) 7-Chlorokynurenic acid is a selective antagonist at the glycine modulatory site of the $N$-methyl-D-aspartate receptor complex. Proc Natl Acad Sci USA 85:6547-6550.

Kim K-T, Westhead EW (1989) Cellular responses to $\mathrm{Ca}^{2+}$ from extracellular and intracellular sources are different as shown by simultaneous measurements of cytosolic $\mathrm{Ca}^{2+}$ and secretion from bovine chromaffin cells. Proc Natl Acad Sci USA 86:9881-9885.

Kohmura E, Yamada K, Hayakawa T, Kinoshita A, Matsumoto K, Mogami H (1990) Hippocampal neurons become more vulnerable to glutamate after subcritical hypoxia: an in vitro study. J Cereb Blood Flow Metab 10:877-884.

Koike T, Martin DP, Johnson EM Jr (1989) Role of $\mathrm{Ca}^{2+}$ channels in the ability of membrane depolarization to prevent neuronal death induced by trophic-factor deprivation: evidence that levels of $\mathrm{Ca}^{2+}$ determine nerve growth factor dependence of sympathetic ganglion cells. Proc Natl Acad Sci USA 86:6421-6425.

Lanier WL, Perkins WJ, Karlsson BR, Milde JH, Scheithauer BW, Shearman GT, Michenfelder JD (1990) The effects of dizocilpine maleate (MK-801), an antagonist of the NMDA receptor, on neurologic recovery and histopathology following complete cerebral ischemia in primates. J Cereb Blood Flow Metab 10:252-261.

Lehninger AL (1975) Biochemistry, 2d ed. New York: Worth.

Lemasters S.I, Guiseppi ID, Nieminen A, Herman B (1987) Blebbing, free $\mathrm{Ca}^{2+}{ }_{i}$ and mitochondrial membrane potential preceding cell death in hepatocytes. Nature 325:78-81.

Manev H, Gavaron M, Guidotti A, Costa E (1989) Delayed increase of $\mathrm{Ca}^{2+}$ influx elicited by GLU: role in neuronal death. Mol Pharmacol 36:106-112

Mayer ML, Westbrook GL (1987) The physiology of excitatory amino acids in the vertebrate central nervous system. Prog Neurobiol 28: 197-276.

Michaels RL, Rothman SM (1990) GLU neurotoxicity in vitro: antagonist pharmacology and intracellular calcium concentrations. $J$ Neurosci 10:283-292.

Murphy SN, Miller RJ (1988) A glutamate receptor regulates $\mathrm{Ca}^{2+}$ mobilization in hippocampal neurons. Proc Natl Acad Sci USA 85 8737-8741.

Murphy SN, Miller RJ (1989a) Regulation of $\mathrm{Ca}^{2+}$ influx into striatal neurons by kainic acid. J Pharmacol Exp Ther 249:184-193.

Murphy SN, Miller RJ (1989b) Two distinct quisqualate receptors regulate $\mathrm{Ca}^{2+}{ }_{i}$ homeostasis in hippocampal neurons in vitro. $\mathrm{Mol}$ Pharmacol 35:671-680.

Novelli A, Reilly JA, Lysko OG, Henneberry RC (1988) Glutamate becomes neurotoxic via the $N$-methyl-D-aspartate receptor when intracellular energy levels are reduced. Brain Res 451:205-212.

Olney JW, Price MT, Samson L, Labruyere J (1986) The role of specific ions in glutamate neurotoxicity. Neurosci Lett 65:65-71.

Onodera H, Sato G, Kogure K (1986) Lesions to Schaffer collaterals prevent ischemic death of CA1 pyramidal cells. Neurosci Lett 68: 169-174.

Orrenius S, McConkey DJ, Bellomo G, Nicotera P (1989) Role of $\mathrm{Ca}^{2+}$ in toxic cell killing. Trends Pharmacol Sci 10:281-285.

Reed KC, Bygrave FL (1974) The inhibition of mitochondrial calcium transport by lanthanides and ruthenium red. Biochem J 140:143155.

Rothman SM (1983) Synaptic activity mediates death of hypoxic neurons. Science 220:526-527.

Rothman SM (1984) Synaptic release of excitatory amino acid neurotransmitter mediates anoxic neuronal death. J Neurosci 4:18841891.

Rothman SM (1985) The neurotoxicity of excitatory amino acids is produced by passive chloride influx. J Neurosci 5:1483-1489.

Rothman SM, Thurston JH, Hauhart RE (1987) Delayed neurotoxicity of excitatory amino acids in vitro. Neuroscience 22:471-480.

Schanne FAX, Kane AB, Young EE, Farber JL (1979) Calcium dependence of toxic cell death: a final common pathway. Science 206: 700-702.

Siesjö BK (1989) Calcium and cell death. Magnesium 8:223-237.

Silverstein FS, Buchanan K, Johnston MW (1986) Perinatal hypoxiaischemia disrupts high-affinity $\left[{ }^{3} \mathrm{H}\right.$ lglutamate uptake into synaptosomes. J Neurochem 47:1614-1619.

Simon RP, Swan JH, Griffiths T, Meldrum BS (1984a) Blockade of $N$-methyl-D-aspartate receptors may protect against ischaemic damage in the brain. Science 226:850-852.

Simon RP, Griffiths T, Evans MC, Swan JH, Meldrum BS (1984b) Calcium overload in selectively vulnerable neurons of the hippocampus during and after ischemia: an electron microscopy study in the rat. J Cereb Blood Flow Metab 4:350-361.

Simon SM, Llinas R (1985) Compartmentalization of the submembrane calcium activity during calcium influx and its significance in transmitter release. Biophys J 48:485-498.

Smith JS, Coronado R, Meissner G (1985) Sarcoplasmic reticulum contains adenine nucleotide-activated calcium channels. Nature 316: $446-449$.

Sugiyama K, Brunori A, Mayer ML (1989) Glial uptake of excitatory amino acids influences neuronal survival in cultures of mouse hippocampus. Neuroscience 32:779-791.

Swan JH, Meldrum BS (1990) Protection by NMDA antagonists against selective cell loss following transient ischaemia. J Cereb Blood Flow Metab 10:343-351.

Thayer SA, Hirning LD, Miller RJ (1988) The role of caffeine-sensitive calcium stores in the regulation of the intracellular free calcium concentration in rat sympathetic neurons in vitro. Mol Pharmacol 34: 664-673.

Van Harrcveld A (1959) Compounds in brain extracts causing spreading depression of cerebral cortical activity and contraction of crustacean muscle. J Neurochem 3:300-315.

Van Winkle WB (1976) Calcium release from skeletal muscle sarcoplasmic reticulum: site of action of dantrolene sodium? Science 193: $1130-1131$

Yamada KA, Dubinsky JM, Rothman SM (1989) Quantitative physiological characterization of a quinoxalinedione non-NMDA receptor antagonist. J Neurosci 9:3230-3236. 